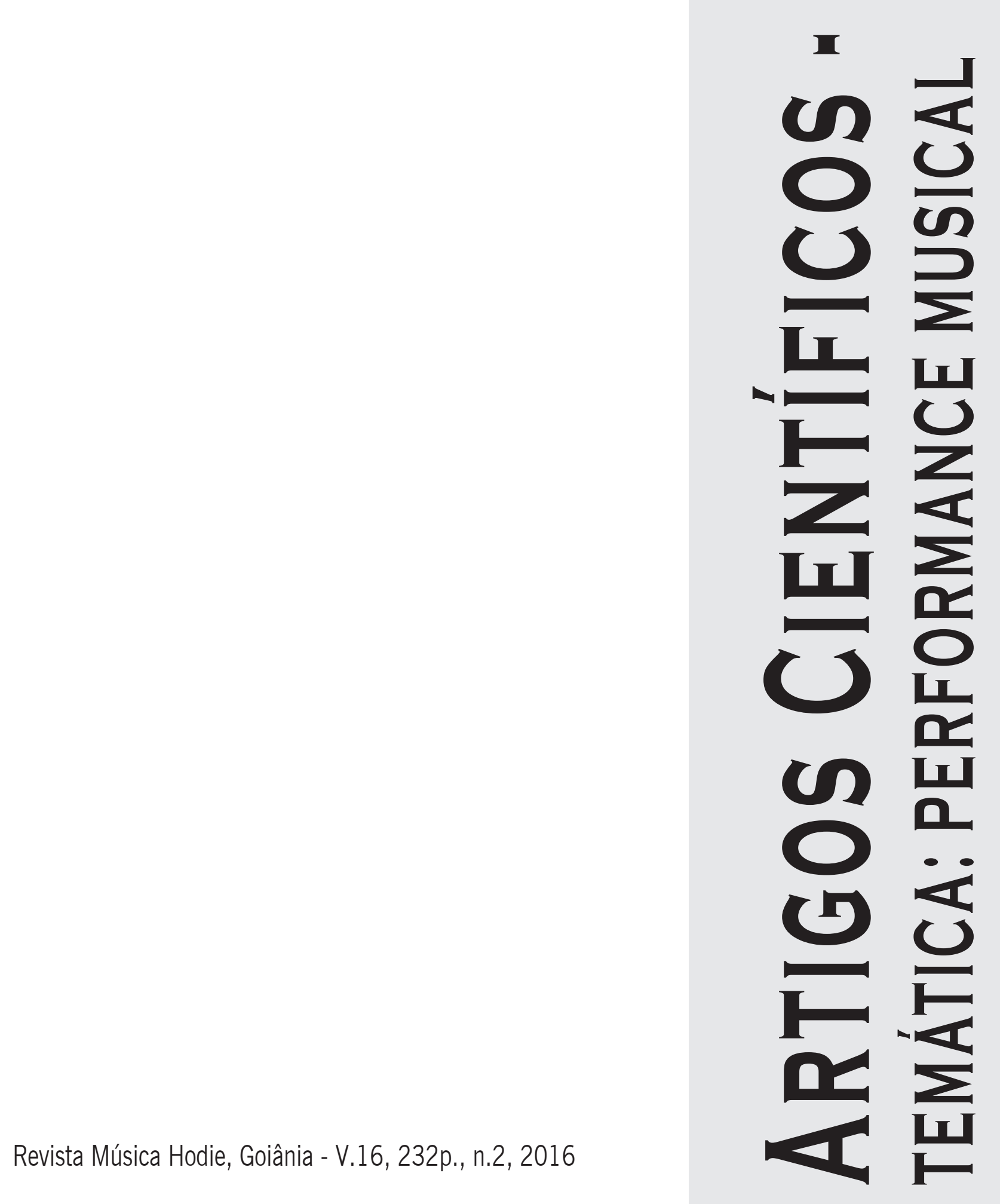




\title{
Abordagens de estudo e performance da obra Responsório ao Vento para violoncelo solo de Silvio Ferraz
}

\author{
Kalyne Teles Valente (Universidade Federal do Rio Grande do Norte, Natal, RN, Brasil) \\ kalynevalente@hotmail.com \\ Fabio Soren Presgrave (Universidade Federal do Rio Grande do Norte, Natal, RN, Brasil) \\ fabiopresgrave@yahoo.com \\ Silvio Ferraz de Mello Filho (Universidade de São Paulo, São Paulo, SP, Brasil) \\ silvioferraz@usp.br
}

\begin{abstract}
Resumo: Com uma produção bastante relevante voltada ao repertório do violoncelo, Silvio Ferraz compôs, em 2012, a peça Segundo Responsório para violoncelo solista e grupo de câmara que, em seguida, originou Responsório ao Vento, versão para violoncelo solo. A peça caracteriza-se pela ideia de continuidade constante do som que se transforma através de diferentes texturas, timbres, dinâmicas e gestos musicais fazendo uso de técnicas estendidas, incluindo grandes seções em sul tasto tocando em três cordas simultaneamente, trinados de harmônicos naturais, trinados com harmônicos naturais abafados, col legno battuto, diferentes tipos de glissando e sons simultâneos de notas harmônicas e não harmônicas que contribuem para uma riqueza de sons e camadas que formam essas texturas. O presente artigo investiga a relação do compositor com o violoncelo e contextualiza Responsório ao Vento dentro da produção de Silvio Ferraz para o instrumento, analisando as influências do compositor e abordando aspectos técnicos e interpretativos da peça a partir de experiências de palco.
\end{abstract}

Palavras-chave: Violoncelo Solo; Performance da música contemporânea; Silvio Ferraz.

Study Approaches and Performance of the Work Responsório ao Vento for violoncello solo by Silvio Ferraz

Abstract: Recognized for his relevant writing for the cello, Silvio Ferraz wrote, in 2012, Segundo Responsório for cello solo and chamber group which followed Responsório ao Vento, a version of the same piece for solo cello. The work is characterized by the idea of continuity of sound moving through different textures, timbres, dynamics and musical gestures. The composer uses extended techniques, such as large sections in sul tasto playing three strings simultaneously, trills of natural harmonics, muffled trills with natural harmonics, col legno batuto, different types of glissando and simultaneous sounds of harmonic and non harmonic notes corroborate to a wealth of sounds and layers that create different textures. This article investigates the relationship of the composer with the cello, and relates Responsório ao Vento to his other works and studies the influences of the composer addressing technical and interpretive aspects of the piece drawn from performance experiences.

Keywords: Violoncello Unnaccompanied, Contemporary music performance; Silvio Ferraz.

Enfoques de Estudio y Ejecución de La Obra Responsório ao Vento para violonchelo solo de Silvio Ferraz

Resumen: Con una producción bastante relevante centrada en el repertorio de violonchelo, Silvio Ferraz compuso, en 2012, "Segundo Responsorio para violonchelo solista y grupo de cámara", a la cual siguió "Responsorio ao Vento", una versión de la misma obra para violonchelo solo. La obra se caracteriza por la idea de una continuidad constante del sonido que se transforma a través de diferentes texturas, timbres, dinámicas y gestos musicales. El compositor hace uso de técnicas extendidas, incluyendo grandes secciones en sul tasto tocando em tres cuerdas simultáneamente, trinos de armónicos naturales, trinos amortiguados con armónicos naturales, col legno battuto, diferentes tipos de glissando y sonidos simultáneos de notas armónicas y no armónicas, que contribuyen a una gran cantidad de sonidos y capas que componen estas texturas. El presente artículo investiga la relación del compositor com el violonchelo y contextualiza "Responsorio ao Vento" dentro de la producción de Silvio Ferraz para el instrumento, analizando las influencias del compositor y abordando aspectos técnicos e interpretativos de la obra a partir de experiencias em el escenario.

Palabras clave: Violonchelo Solo; Interpretación de la música contemporánea; Silvio Ferraz.

Pode-se considerar Silvio Ferraz um dos compositores brasileiros com maior produção para o violoncelo na atualidade. Dentre peças para violoncelo solo, duos, concertos, música de câmara e combinações com live eletronics, entre 1999 e 2013 Ferraz escreveu aproximadamente vinte obras que colocam o instrumento em posição de destaque, explorando suas possibilidades sonoras, timbrísticas e fazendo uso de recursos que levam o intérprete a buscar um estudo criativo, a fim de que possa executar as novas técnicas esten- 
didas propostas. Somam-se a este número ainda três Ricercares para cello solo compostos no início de 2014.

A atração do compositor pelo violoncelo se dá face à sonoridade do instrumento em especial pela riqueza espectral, característica explorada em suas composições. Em entrevista à Kalyne Valente, o compositor descreve o seu interesse na composição para o instrumento da seguinte forma:

Dentre as cordas, o cello tem maior precisão que o contrabaixo e mais presença de som que uma viola. Os pizzicatos do violoncelo são mais ressonantes. Também tem um leque maior de posições para cordas duplas. Pela dimensão e espessura das cordas tem diversas das possibilidades de multifônicos e jogos de harmônicos que tem um contrabaixo. Ainda tem uma coisa incrível que é a transparência espectral que se consegue apenas modificando a pressão de arco. Isto sem contar que uma pequena pancada com os dedos no tampo produz um som de percussão médio-grave também espectralmente rico. (VALENTE; FERRAZ, 2014, p. 29)

O repertório para violoncelo de diferentes épocas exerce forte influência sobre o compositor e podemos aqui destacar alguns desses nomes, que vão desde a música para viola da gamba (Sainte Colombe, por exemplo), passando por Bach, Brahms, Villa Lobos e Luciano Berio. Silvio Ferraz destaca também a capacidade que o violoncelo possui em remeter o ouvinte a sonoridades de elementos não musicais, como por exemplo, no caso de Ferraz, o som dos “carros de boi”, típicos da cultura do interior do Sudeste do Brasil, sua região natal, e que pode ser encontrada em algumas de suas composições (FERRAZ, 2014). Exemplo disto é a peça Linhas Soltas, Linhas de Passagem e Linhas Tortas (2006) para violoncelo e piano.

Ao longo de sua carreira, o compositor estudou diversos instrumentos como flauta, piano, tuba, trompa e percussão e teve contato com diversos instrumentistas e grupos de câmara com os quais pôde observar e experimentar gestos musicais que mais tarde foram trabalhados em suas composições. Em 2012 deu início ao estudo do violoncelo, o que lhe permitiu adquirir um conhecimento mais minucioso dos recursos e das possibilidades de execução das técnicas estendidas que tanto proporcionou uma ampliação como uma maior restrição no uso dos recursos, uma vez que, através desta troca de papéis entre compositor/ violoncelista, o mesmo conscientizou-se ainda mais da dificuldade e/ou impossibilidade de tais execuções (VALENTE; FERRAZ, 2014, p. 26).

É assim que sua escrita anterior à prática do instrumento pode ser bem observada na obra Luna, mujer y toro (1999), que foi sua primeira peça composta para violoncelo solo e com uma ampla paleta sonora. Um dos maiores desafios para o intérprete nesta peça inicia-se na forma como foi usada a técnica de scordatura, devendo as cordas ré e dó ser afinadas uma oitava abaixo, deixando-as quase livres de pressão. Além disso, as grandes extensões de mão esquerda e o uso de quartos de tom e sons multifônicos apelam para grande virtuosidade técnica e caracterizam o que o compositor chama de uma "gestualidade mal calculada”, pois mesmo antes de conhecer mais profundamente o violoncelo e, em geral, os instrumentos para os quais compôs, procurou sempre ter em mente a fisicalidade do instrumento e o gestual do instrumentista (VALENTE; FERRAZ, 2014, p. 26).

Já bastante diferente é a escrita de seu Segundo Responsório (2013), primeira escrita composta depois que o compositor iniciou seus estudos de violoncelo. É bastante evidente nesta obra o conhecimento do compositor quanto ao mapa do espelho do instrumento, assim como a forma como a que ele faz uso das cordas duplas e extensões de mão esquerda. Perceptível também é o domínio ainda maior quanto ao uso dos harmônicos naturais com- 
binados às "notas presas" e de efeitos que o compositor chama de "trilo tímbrico", ${ }^{1}$ escritos de forma que o violoncelista não precise de grandes aberturas e nem grandes movimentos de mão esquerda. Diversos desses efeitos idiomáticos e até mesmo de passagens mais líricas presentes em suas peças também devem-se a sua prática de improviso (modal a atonal livre) durante seu estudo ao violoncelo (FERRAZ, 2014, s/p).

De acordo com o compositor, sua relação com os instrumentistas para quem compôs algumas de suas obras inspiraram seu processo criativo de alguma forma. Para Ferraz (2014), a "técnica e o repertório que o instrumentista vive que acabam alimentando" suas peças. Algumas de suas composições surgiram a partir de conversas sobre concepções de estilo e performance com os intérpretes e outras foram sofrendo alterações na escrita à medida que o compositor também mudava sua concepção sobre a obra. Exemplo disso é a peça Lamento Quase Mudo (2005) para violoncelo solo composta para a violoncelista Tereza Cristina Rodrigues e que, mais tarde, após sua estreia, foi retrabalhada pelo compositor sofrendo diversas alterações até sua versão final, em 2006. Posteriormente, em 2008, Ferraz alterou diversos trechos da seção central por achar que o efeito esperado poderia ter sido atingido de outras formas. Em concerto no ano de 2014, o violoncelista André Micheletti retrabalhou ainda mais uma vez com o compositor a versão anterior a de 2006, e recriou através de ajustes técnicos a versão original com o compositor. Escrever versões da mesma peça também é uma prática recorrente de Silvio Ferraz, ora por motivos de necessidade criativa, ora por viabilizar as performances com diferentes formações instrumentais conforme as circunstâncias. Silvio Ferraz trabalha em constante colaboração com os intérpretes de suas obras. Nesse sentido, para o compositor, a finalização da escrita é apenas um dos passos do processo de suas peças que estão em constante transformação.

De modo a exemplificar a escrita do compositor, analisaremos neste trabalho aspectos técnicos e interpretativos da peça Responsório ao Vento, cujas estreias das versões para violoncelo e grupo de câmara e para violoncelo solo foram realizadas pela autora deste trabalho no ano de 2013, assim como também a versão para violoncelo e percussão, ocorrida em 2014, intitulada Resposta à Nonada.

\section{Aspectos técnico-interpretativos de Responsório ao Vento}

A peça Segundo Responsório é uma das obras de Silvio Ferraz que possui múltiplas versões. Composta em 2012, sua primeira versão foi encomendada pela Fundação Nacional de Artes para a ocasião da XX Bienal de Música Brasileira Contemporânea sediada na cidade do Rio de Janeiro em outubro de 2013, para flauta em sol, clarinete baixo, piano e violoncelo solista, tendo sido, no mesmo ano, estreada pela autora deste trabalho. Em novembro de 2013 recebeu sua segunda versão, para violoncelo solo, sob o título Responsório ao Vento e em 2014 a versão para violoncelo e percussão, ou Resposta à Nonada. Ambas versões também estreadas pela autora na cidade de Natal, Rio Grande do Norte. Responsório ao Vento e Respostaa Nonada quase não diferem entre si quanto a parte do violoncelo, mas diferem em alguns aspectos da primeira versão para grupo de câmara. Assim como ocorrido em Lamento Quase Mudo, o compositor fez alterações de notas, retirou e acrescentou trechos. Uma dessas alterações, por exemplo, foi o acréscimo da técnica “arco battuto” e “tapping” encontrada nas duas últimas versões, e que por sua vez não possuem pizzicatos bártok, existentes na primeira, enquanto que Resposta à Nonada diferencia-se de Responsório ao Vento apenas no fato de mesma finalizar com batidas no tampo do violoncelo com os dedos, semelhante ao efeito utilizado por Luciano Berio em Sequenza XIV. 
Ao dividir o conjunto de suas obras recentes em duas categorias distintas: os Responsórios e os Ritornelos, o compositor observa em sua prática duas temporalidades distintas na sua escrita. Enquanto os Ritornelos constituem peças mais movidas, com uso de tempos estriados, ${ }^{2}$ os Responsórios fazem parte daquelas "de som contínuo ou de ritmo continuo e pulsante", com sensação de grande continuidade e que remete ao ouvinte um caráter quase místico (FERRAZ, 2014, s/p). Segundo o compositor, essa característica se deve à influência da música ritualística, dos mantras e de peças emblemáticas de compositores como Ligeti e Stockhausen, especialmente em suas obras Atmospheres, Continuum, e Stimmung, respectivamente, dentre outras influências. Em entrevista a autora, Ferraz compara esta música de "passagens planas" com a imagem do deserto, onde quase nada muda.

São três os Responsórios de Silvio Ferraz: Responsório: segundo carro de boi (2009), Segundo Responsório (2012) e Responsório de Domingo de Ramos (2013). O primeiro foi originalmente escrito para violoncelo, piano e contínuo e, em 2013, ganhou uma segunda versão para violoncelo solo intitulado Responsório: terceiro carro de boi; o segundo possui três versões como já mencionado; e o terceiro, composto para violoncelo e orquestra.

De acordo com Ferraz (2014, p. 27), a ideia de jogo entre solista e um grupo instrumental presente nos responsórios teve como referência os concertos barrocos. Mas é importante observar que o próprio termo "responsório" nos remete à ideia de religiosidade, uma vez que consiste num tipo de canto litúrgico. Esta ideia de religiosidade, de certa forma, também está presente em várias outras peças do compositor. Para Ferraz (2014, p. 29), este imaginário artístico musical é proveniente de seu contato com um universo católico ritualístico das procissões que fazem parte dos costumes do interior de Minas Gerais e São Paulo, e que o compositor chama de "religiosidade quase pagã de um povo", termo emprestado dos heterônimos de Fernando Pessoa e Antônio Móra.

A ideia de continuidade sonora constante com inserções de movimentos que surgem através da mudança de timbres, ora com harmônicos naturais ${ }^{3}$ ora com trilos de harmônicos abafados, constituem uma das características principais da peça. No início da mesma verificamos o que o compositor denomina de "trilo tímbrico" consistindo na execução do harmônico natural dó com o quarto dedo na corda sol e abafando a mesma com os demais dedos (Exemplo 1). Nota-se que este "jogo de timbres" ocorre com ritmos precisos como quiálteras de cinco, seis e sete colcheias.

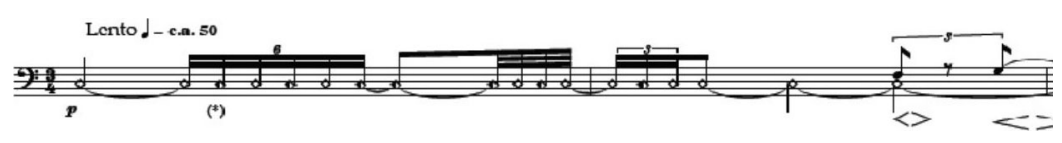

Exemplo 1: Notação do efeito de "trilo tímbrico" em quiálteras.

\subsection{Dedilhados}

Na primeira parte da peça Ferraz emprega simultaneamente notas presas e harmônicos naturais, o que demonstra um conhecimento preciso do mapa do espelho do instrumento. Consequentemente, a escrita não requer grandes mudanças ou extensões de posições e aberturas de mão esquerda. Apesar disso, torna-se necessário em diversos momentos buscar soluções estratégicas de dedilhados. Na seção destacada na figura abaixo, por exemplo, que corresponde aos primeiros compassos da peça, onde temos nota presa tocada simultaneamente com nota harmônica seguida de nota presa com "trilo tímbrico", me pareceu interessante escolher um dedilhado que permitisse os outros dedos abafarem a corda sem 
correr o risco das notas falharem (Exemplo 2). A partir de nossas performances sugerimos o dedilhado indicado no exemplo a seguir.

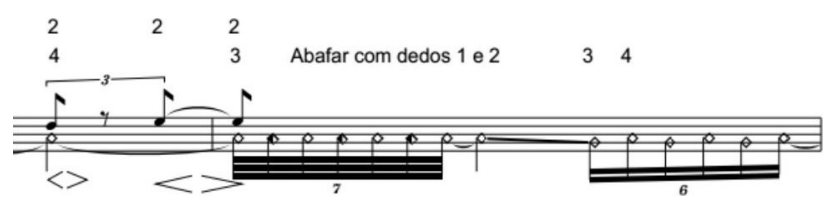

Exemplo 2: Sugestão de dedilhado para o "trilo tímbrico" do Responsório ao Vento.

No dedilhado proposto acima, a nota "sol" com segundo dedo e substituição do quarto pelo terceiro dedo no "dó" harmônico natural permite que na sequência de trinado o violoncelista abafe a corda sol com o primeiro e segundo dedos, liberando a nota presa. Não há rigorosidade neste caso que a colcheia "sol" dure seu tempo integralmente, e sim que inicialmente ambas soem simultâneas e que, em seguida, o efeito do "trilo tímbrico" seja o mais audível possível (FERRAZ, 2013, s/p). Em geral, em torno de toda a peça a questão do efeito sonoro desencadeado pelas texturas resultantes das técnicas estendidas, e até mesmo da ideia de continuidade e elasticidade do mesmo, são mais determinantes que a rigorosidade rítmica escrita (FERRAZ, 2013, s/p). Desta forma, o dedilhado pode ser pensado de acordo com a intenção de valorizar um efeito, uma dissonância, ou uma passagem mais cantábile.

Outro exemplo disto surge no compasso 49 (Exemplo 3) no qual, visando otimizar a valorização da dissonância resultante do intervalo harmônico de segunda menor entre dó sustenido e ré natural, optamos por substituir o quarto dedo da nota ré, pelo polegar e executar o dó sustenido com o terceiro dedo na corda ré. Desta forma a abertura (extensão) da mão torna-se menor do que a da outra opção de dedilhado (nota ré na corda ré e dó sustenido na corda lá) tornando a execução mais confortável para "cantar” a passagem.

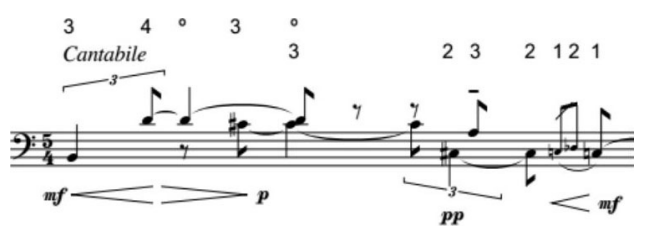

Exemplo 3: Dedilhado proposto para o compasso 49 de Responsório ao Vento.

No compasso 50 o uso dos harmônicos naturais também simplifica a execução da passagem. A fim de que não haja necessidade de tocar harmonicamente o intervalo sol-lá com notas presas em posição de capotasto, pode-se fazer uso dos harmônicos naturais nas cordas sol e ré. No exemplo abaixo (Exemplo 4) verificamos a escrita deste compasso encontrada na versão para violoncelo solo, ou seja, sem o símbolo de harmônico natural $\left(^{\circ}\right)$ sobre as notas sol e lá, o que pode induzir o intérprete a um dedilhado com notas presas.

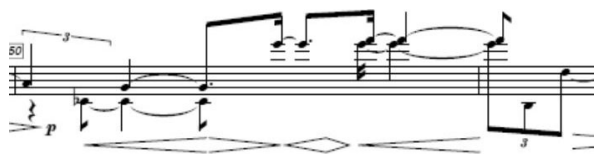

Exemplo 4: Escrita do compasso 50 na versão para violoncelo solo.

Em Segundo Responsório, versão para quarteto, esta proposta já vem explícita na edição do compositor através do símbolo de harmônico $\left(^{\circ}\right)$ sobre as duas notas indicando que a mesma passagem pode ser tocada com um dedo no harmônico natural sobre a nota 
dó na corda sol e o outro dedo no harmônico natural sobre a nota lá na corda ré, assim como mostra o exemplo abaixo (Exemplo 5). Dessa forma toda a sequência permanece em posições próximas e mais confortáveis para a mão do violoncelista.

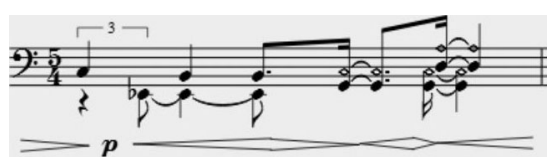

Exemplo 5: Execução da passagem com harmônicos naturais. Posição real dos dedos nas cordas.

\subsection{Glissandi}

Também destaca-se o uso dos glissandos na peça. Ferraz faz uso de dois tipos diferentes, os quais denomina de glissando reto e glissando com pequeno portamento (Exemplo 6). No primeiro, a duração do glissando entre as notas deve ser homogênea, de forma que o portamento tenha a mesma duração entre as duas notas, o que exige atenção do violoncelista quanto a diferença em executá-lo em posições mais agudas e em posições mais graves. Sobre este tipo de glissando o compositor afirma:

O glissando reto ele é o mais chato de fazer... pois você tem de imaginar que no grave a mudança de posição é mais lenta (tem mais espaço entre uma nota e outra) e no agudo é mais rápida (menos espaço entre uma nota e outra)... ou seja, é como um glissando de voz em que a passagem entre cada nota tem sempre a mesma velocidade. (VALENTE; FERRAZ, 2014, p. 31)

O glissando com pequeno portamento, conforme o próprio desenho da escrita, tem um portamento mais lento na nota que se inicia e um súbito para a nota de chegada (VALENTE; FERRAZ, 2014, p. 31). Este tipo de glissando também é usado em outra obra sua, Litania, para quarteto de cordas.

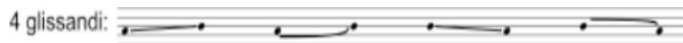

Exemplo 6: Representação de Glissando reto e glissando com pequeno portamento em Segundo Responsório.

O compositor Iannis Xenakis fez importantes estudos sobre este recurso. Através de estudos matemáticos ele observou que diferentes velocidades são necessárias de acordo com a distância entre uma nota e outra para alcançar a linearidade do glissando (VALENTE; FERRAZ, 2014, p. 31). Na peça Metastasis (1953-54), por exemplo, ele representa através de gráfico o glissando das cordas. Esse gesto musical foi um dos primeiros a serem trabalhados em suas peças para cordas (FERRAZ, 2014, s/p) e uma das mais representativas que utilizam esse recurso é Nomos Alpha (1965-66) para violoncelo solo, dedicada a Siegfried Palm.

\subsection{Cordas triplas}

Outro elemento de técnica estendida que destaca-se na parte central da peça é o uso de três cordas tocadas simultaneamente. Para tal, o compositor indica na partitura que o arco nas mesmas deve ser tocado "muito em sul tasto", ${ }_{4}$ quase próximo a mão esquerda 
em posições agudas no espelho do violoncelo. Ferraz (2014, s/p) compara a sonoridade desta passagem com a da técnica "boca chiusa", onde torna-se importante ter a sensação de distancia do som. Tocar efetivamente sobre o espelho torna-se um requisito indispensável para o violoncelista, uma vez que a ângulo entre as cordas nesta região é menor, permitindo tocar as mesmas de forma audível. Por se tratar de uma longa passagem e de não ser uma região da corda tão habitual ao violoncelista, a indicação do compositor sobre "tocar quase muito perto da mão esquerda" pode ser tratada como uma eficiente estratégia se pensar na sensação física de que elas estas estão realmente próximas e que assim devem ser mantidas.

Nesta passagem verificamos uma série de elementos característicos dos Responsórios do compositor. Segundo Ferraz, “...quando há muito movimento o ouvido vai pro movimento, quando tudo está parado ele procura o que se mexe... e é aí que dá pra brincar com o timbre" (VALENTE; FERRAZ, 2014, p. 27), descrevendo assim a sensação sonora de três cordas ressoando ao mesmo tempo onde duas encontram-se paradas, como pedais, e uma atrai o ouvinte pelo movimento melódico da corda intermediária, na maior parte do tempo em intervalos muito próximos (Exemplo 7). Estes intervalos, em sua maioria, movem-se através de pequenos portamentos e glissandos, podendo nos remeter à ideia de aboio, canto de caráter lamentoso comum nos interiores da Região Nordeste, Centro-Oeste e Sudeste, em especial, de Minas Gerais, e que exerce forte influência em suas composições. Mas também pode nos remeter a ideia de ritual, da música dos mantras, com longos pedais:

Para muitos da minha geração houve um momento em que o caminho para reestabelecer contato com o público seria o do ritual. E a música ritual tem forte esta questão da continuidade. Do som contínuo ou do ritmo continuo e pulsante. E os exemplos de continuidade são muitos. Na música experimental foi forte para mim a obra Stimmung de Stockahausen, Atmospheres e Continuum de Ligeti, as obras pulsantes como Music for 18 de Steve Reich, e ainda tem por trás de tudo isto os solos de Jimmie Hendrix em Little Wing... (VALENTE; FERRAZ, 2014, p. 27)

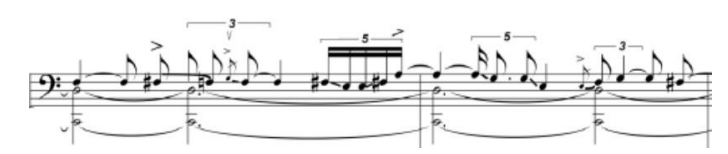

Exemplo 7: Trecho de três cordas simultâneas em sul tasto.

\subsection{Apojaturas}

Neste contexto onde o som é contínuo e pulsante, o movimento das apojaturas desempenha um papel importante no destaque do movimento. De forma geral, as apojaturas na música do século XX tendem a serem tocadas o mais rápido possível (PRESGRAVE, 2014, s/p) e, em passagens de paisagens planas, como é o caso de Responsório ao Vento, elas acabam por criar um contraste com o ritmo lento da peça. Ferraz afirma que mantém esta relação com a notação da apojatura e isso naturalmente "acaba tirando a precisão do tempo tornando as frases mais vivas e com pequenas irregularidades" mas que apesar disso, também afirma que sempre manteve-se maleável com as decisões do intérprete (VALENTE; FERRAZ, 2014, p. 31).

Um outro aspecto a se ressaltar com relação às apojaturas na escrita de Silvio Ferraz é sua relação com a música de Messiaen e com a transcrição de cantos de pássaros. Esta ideia de execução rápida das apojaturas, especialmente naquelas de uma, duas ou três notas vem da influência do Style Oiseaux, ou "estilo pássaro". ${ }^{5}$ Segundo Ferraz: 
ções de cantos de pássaros e usei muitos destes cantos em peças minhas. Então muitas vezes apojaturas com uma, duas ou mesmo três notas, são para serem realizadas bem rápido deixando ouvir apenas o intervalo entre a última nota do grupeto e a nota de chegada. (VALENTE; FERRAZ, 2014, p. 32)

\subsection{Complexidade rítmica}

Apesar de fazer parte do estilo de peças menos movidas do compositor, Responsório ao Vento também traz consigo certa complexidade rítmica. Destacam-se, em grande parte de suas peças, o uso de quiálteras e tempos deslocados que tiram a sensação de pulso marcado, proporcionando tempos irregulares concomitantemente a mudanças de andamento. Em uma das partes mais movidas da peça, por exemplo, ele utiliza uma série de quiálteras de fusas e semicolcheias com indicações numéricas que determinam proporções, como 6:4, 9:8, 22:16, 20:16, 30: 32, etc. No trecho abaixo verificamos, por exemplo, que as indicações 14:12, 18: 16 e 22:16 significam, respectivamente, tocar 14 semicolcheias no espaço equivalente a 12, em seguida, 18 semicolcheias no espaço equivalente a 16 e, finalmente, 22 no espaço equivalente a 18 (Exemplo 8). Na prática, para o compositor e para o intérprete, mais importante do que executar a passagem com precisão matemática é compreender que a semicolcheia deve se tocada um pouco mais rápida do que seu padrão métrico do compasso quaternário. Nota-se que na segunda e terceira quiáltera do exemplo abaixo a quantidade de semicolcheias varia dentro da mesma proporção métrica, que no caso é 16, mas diferem na quantidade de notas a serem tocadas, 18 e 22, respectivamente, o que significa que deve haver uma diferença clara entre as duas, devendo a segunda ser executada proporcionalmente mais rápida que a primeira.

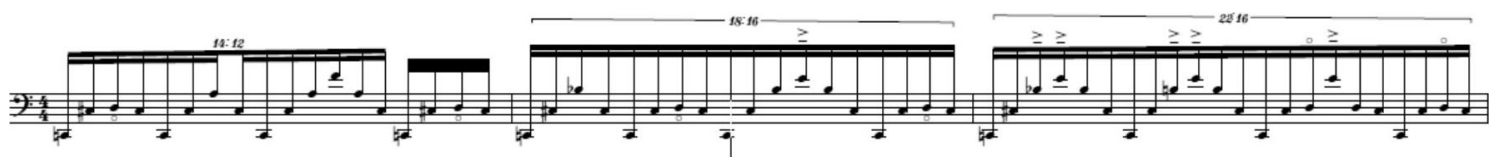

Exemplo 8: Trecho de quiálteras.

Nas sessões menos movidas o uso das ligaduras que conectam as quiálteras entre si e, a outros ritmos, também eliminam a sensação de pulso. Sobre isto Ferraz afirma:

Emprego as quiálteras no sentido simples de criar uma mudança de andamento súbita entre frases e deixar assim o metro da peça cambaleante. Isto acontece sobretudo quando ligo o último beat de uma figura em tempo ordinário (quatro colcheias em um compasso 2/4) com o primeiro de uma quiáltera (uma quintina no compasso seguinte também em 2/4). Isto faz retirar o pé do chão, é como se o tempo perdesse o pé, mas ao mesmo tempo parecesse regular. (VALENTE; FERRAZ, 2014, p. 30)

Segundo o compositor, o ritmo e tempo da peça devem ser obedecidos, porém, por gerarem um tempo liso, ${ }^{6}$ dão ao intérprete possibilidade de brincar com o ritmo "cambaleante" (FERRAZ, 2014, s/p). De fato, minha experiência ao realizar a peça vai de encontro ao projeto do compositor: parece-me de fato necessário que a interpretação da peça atenha-se menos à precisão das prolações indicadas que à elaboração de uma agógica e uma respiração temporal própria. Para tal, o método de estudo utilizado para uma melhor compreensão rítmica da peça foi marcar na partitura os tempos de cada compasso (Exemplo 9). Este método foi de fundamental importância especialmente para a performance de Segundo Responsório e Resposta a Nonada, versões de câmara, uma vez que a atenção em encaixar todas as vozes dentro desta rítmica complexa deve ser cuidadosa. 


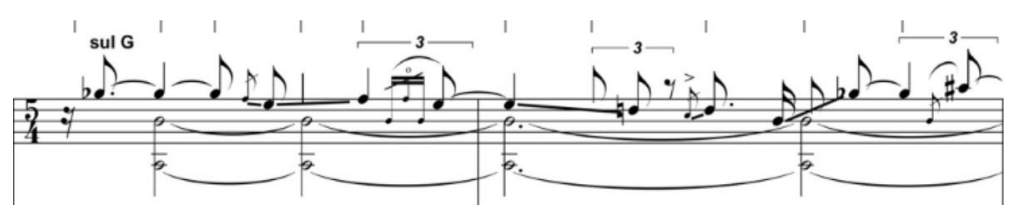

Exemplo 9: Estratégia de estudo: marcação de cada tempo dentro dos compassos.

\subsection{Efeitos percussivos com o arco e com a mão esquerda}

Em Responsório ao Vento Ferraz utiliza efeitos percussivos com o arco e com a mão esquerda. Estes mesmos trechos se mantém inalterados em Resposta à Nonada mas diferem em Segundo Responsório, a primeira versão, que utiliza pizzicatos bártok na parte do violoncelo. Segundo Ferraz, o motivo da mudança se deve ao fato de que na versão solo, e mesmo no duo com a percussão, o violoncelo ganha mais agilidade com o "arco batutto" e com o “tapping”, enquanto que a versão para quarteto, naturalmente o pizzicato bártok ganha esta qualidade pelo fato dos quatro instrumentos (violoncelo, piano, flauta e clarone) o fazerem ao mesmo tempo (FERRAZ, 2014, s/p).

O termo battuto, que também vem do termo italiano battere, ou bater, se refere ao arco saltado na corda, também muito desenvolvido de forma a produzir diferentes sonoridades na música do século XX. De acordo com Strange (2001):

Em termos tradicionais, o arco saltado significa um salto controlado (spicatto, staccato, jetté, saltando). Na literatura mais atual a técnica pode se referir a um salto mais cuidadosamente controlado por indicação de um número específico de saltos, por exemplo, ou indeterminado. (p. 33)

Esse salto controlado do arco, que também podemos comparar ao golpe de ricochet, pode surgir na literatura também em diferentes dinâmicas. Na peça o compositor indica textualmente que a notação utilizada significa "um forte arco battuto (com rebote)", devendo o violoncelista saltar com a madeira do arco usando o rebote do golpe inicial e ainda enfatiza a dinâmica em fortíssimo com a expressão "violento". Em minha experiência com a peça, esta expressão, associada ao arco batutto, intuitivamente foi interpretada como $\mathrm{col}$ legno battuto por se tratar de uma dinâmica forte num gesto percussivo do arco/crina contra a corda, criando um maior contraste com o contexto anterior e posterior à passagem. Finalmente enfatizamos aqui a importância da interação entre intérprete e compositor, por ter sido um trecho no qual Ferraz, durante seu processo de composição, optou por escrever apenas arco batutto para "evitar embates com intérpretes mais conservadores" (FERRAZ, 2013, s/p), uma vez que, a execução desta técnica, aliada à uma dinâmica forte, requer um golpe agressivo da vareta contra a corda do violoncelo, o que nem todo músico está disposto a realizar a menos que tenha um arco/instrumento apropriado, razão pela qual fiz uso de um tipo de arco específico para a execução desta peça (fibra de carbono). Com a intenção de garantir maior fidelidade à escrita, tomei uma liberdade que "reflete a própria partitura" (FERRAZ, 2014, s/p)

A expressão "col legno", literalmente, significa "com a madeira”, ou seja, tocar com a madeira do arco. Este é um recurso sonoro que já vem sendo utilizado desde épocas anteriores no repertório dos instrumentos de cordas friccionadas e que teve sua amplitude de possibilidades de uso e combinações desenvolvidas principalmente no século XX. Em Harke Harke do compositor renascentista Tobias Hume, para viola da gamba, por exemplo, textualmente há a seguinte indicação na partitura: "percutir isso com o lado de traz do ar- 
co”, o que já seria o "col legno battuto” (PADOVANI; FERRAZ, 2011, p. 14). De acordo com Strange (2001):

Há várias formas de tocar col legno (...). Esta ação pode ser aplicada em qualquer parte do instrumento: col legno sub ponticello, col legno sul ponticello, col legno posição normal, col legno sul tasto, col legno no corpo do instrumento. Há duas maneiras básicas em que a vareta do arco pode gerar som no violino. A primeira é golpear (col legno battuto) e a segunda é usar um golpe legato, mantendo a vareta em contato com o instrumento durante todo o curso (col legno trato). (p. 35)

A outra técnica utilizada por Ferraz neste mesmo trecho, associada ao "arco battuto", é a de percutir com os dedos da mão esquerda sobre a corda, fazendo uso de um "X" na "cabeça de nota" percutida (Exemplo 10). Conhecida como "tapping" ou "Fingerschlag" (MESSINA, p. 25), essa técnica pode produzir dois tipos de sonoridades, uma, resultante da articulação do dedo sobre o espelho e outra, da reverberação da nota. Luciano Berio também utiliza esse recurso em Sequenza XIV em longas sequências de semicolcheias porém com diferente notação.

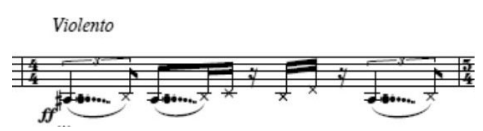

Exemplo 10: Sequência de "arco battuto" e "tapping" em Responsório ao Vento.

\subsection{Bariolage}

Tendo o compositor tido influências determinantes do estilo e repertório barroco pra violoncelo e viola da gamba,como Sainte Colombe, Bach e Vivaldi, é possível identificarmos algumas técnicas que nos remetem à sonoridades desse período em Responsório ao Vento. Uma delas é a "bariolage" que, segundo Strange (2001, p. 32), é uma técnica que "explora os vários timbres de uma mesma nota em diferentes cordas”. Podemos encontrá-la por exemplo no Prelúdio da Suite VI para violoncelo solo de Johan Sebastian Bach (Exemplo 11). Esta técnica é aplicada na música contemporânea explorando diversos timbres e possibilidades de combinações. Em Noturno para quarteto de cordas de Mauricio Kagel, por exemplo, é combinada "bariolage" com articulações e ritmos diferentes em cada instrumento criando uma complexa textura de timbres com a polirritmia gerada (STRANGE, 2001, p. 32).

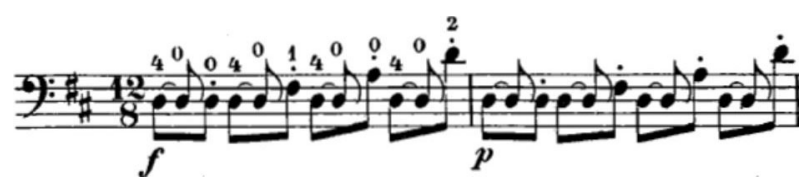

Exemplo 11: "Bariolage" no Prelúdio da Suíte VI para violoncelo solo de J.S.Bach.

Em Responsório ao Vento uma das situações em que o compositor faz uso desta técnica é explorando as diferentes sonoridades da nota ré com variações de quiálteras (Exemplo 12).

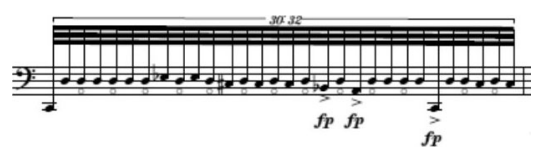

Exemplo 12: "Bariolage" em Responsório ao Vento. 
Assim como também utiliza na sessão final da peça para diferenciar a sonoridade da nota lá repetidas vezes em uma longa sequência de arpejos (Exemplo 13).

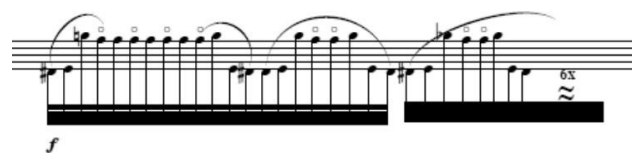

Exemplo 13: "Bariolage" na sessão final.

A sessão final da peça é caracterizada por uma sucessão de padrões diferentes de arpejos notados com o número aproximado de vezes que devem ser repetidos (Exemplo 14).

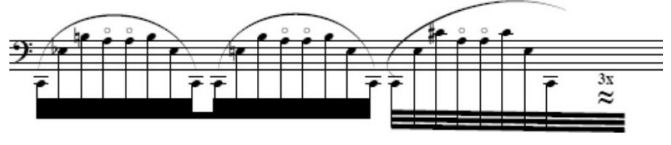

Exemplo 14: Arpejos em Responsório ao Vento.

Aqui verificamos influência da música de Bach, especialmente dos arpejos do Prelúdio da Suite III para violoncelo solo (Exemplo 15) mantendo uma semelhança dos padrões arpejados, rápidos, ligados e com uma sensação da nota grave ressoando como um pedal.

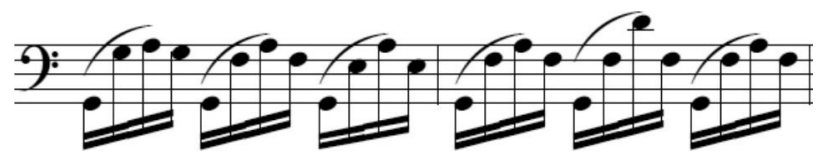

Exemplo 15: Arpejos no Preludio da Suite III, em Dó Maior, BWV 1009 para violoncelo solo de J,S.Bach.

\section{Considerações finais}

O laboratório realizado entre compositor e instrumentista que originou este trabalho nos reiterou a importância da pesquisa para o campo da performance, uma vez que, conhecer contextos, buscar origens, experimentar possibilidades de execução ou mesmo relacionar elementos musicais a sonoridades diversas podem ser elementos determinantes para uma maior compreensão e entendimento por parte do intérprete sobre aquilo que o compositor buscou, consciente ou inconsciente, transcrever através de sua partitura.

Dessa forma, ter o conhecimento de que o compositor sofreu algum tipo de influência da música barroca, por exemplo, em especial de uma das suítes de Bach, ou mesmo do repertório para outro instrumento, como viola da gamba, pode mudar nossa concepção de sonoridade ao executar determinada passagem. Ou mesmo saber que sua concepção de apojatura foi buscada no canto dos pássaros, o que pode levar o intérprete a pensar como tal e buscar uma verossimilhança da sua articulação com o som de origem do compositor. Tomar conhecimento de elementos sonoros que fizeram parte de algum momento de sua vida (como o som dos carros de boi, as procissões, o cânticos de aboio) e de compositores que exerceram alguma influência sobre sua obra, como Ligeti, Stockhausen, Steve Reich ou Luciano Berio, podem tornar o imaginário do instrumentista muito mais rico e criativo.

As técnicas estendidas na música contemporânea não precisam "ser um fim nelas mesmas" (ANTONINI, apud PADOVANI-FERRAZ, 2011, p. 16). É possível e, talvez necessário na maioria das vezes, que o intérprete atribua um caráter dramático às mesmas, muitas vezes já podendo estar presente na intenção do compositor. Em nossa pesquisa verifica- 
mos que em Responsório ao Vento vários desses carácteres são passíveis de observações e do quanto cada versão muda completamente a roupagem da peça, mesmo com pouquíssimas diferenças na parte do violoncelo. Para o intérprete e para o ouvinte, a sensação é como se Segundo Responsório, Responsório ao Vento e Resposta a Nonada constituíssem três peças distintas e é nesse ponto que verificamos a grande destreza do compositor.

Pontuamos também que, especificamente no caso desta peça, esta relação entre intérprete e compositor não foi somente o ponto de partida para este trabalho como também o ponto determinante de minha performance desde sua estreia, na XX Bienal de Música Contemporânea Brasileira. Na ocasião, tendo apenas quatro dias para realizar estudo, compreensão da peça, deslocamento à cidade, ensaio e concerto, as trocas de informações com o compositor foram determinantes e de extrema importância para que tudo fosse possível. Desde então, a cada performance, entrevista, troca de e-mails e, principalmente cada contato de ensaio com o compositor, enriqueceram e inovaram cada vez mais a compreensão de cada elemento técnico, do caráter de cada versão, de cada sonoridade e também da negociação entre aquilo que o compositor idealiza e o que é possível de ser feito pelo intérprete. Sendo assim, "as técnicas estendidas são um domínio aberto de conversa entre intérprete e compositor” (FERRAZ, 2014, s/p).

\section{Notas}

1 Efeito gerado abafando os harmônicos naturais com os dedos. (FERRAZ, 2013, s/p)

2 Termo proposta por Pierre Boulez em seu livro Penserla Musique Aujoued'hui, traduzido no Brasil por A Música Hoje: "o espaço das frequências pode sofrer duas espécies de cortes: uma, definida por um padrão, renovar-se-á regularmente, a outra, imprecisa, não determinada, mais exatamente, intervirá livre e irregularmente” (BOULEZ, 1972, p. 84)

3 "Som harmônico produzido a partir de uma corda solta. Os harmônicos naturais são classificados pela ordem em que os parciais aparecem na série harmônica, i.e., segundo harmônico natural, terceiro harmônico natural, quarto harmônico natural, e assim por diante" (CARDOSO, 2000, p. 87).

4 Técnica de tocar com a crina próxima ao espelho, em sul tasto o arco "para a vibraçãolivre da corda, cancelando os harmônicos agudos" (FALLOWFIELD, 2008, p. 34).

5 "Styleoiseaux".

6 "O tempo amorfo é comparável à superfície lisa, o tempo pulsado à superfície estriada; eis por que, por analogia, denominarei as duas categorias assim definidas tempo liso e tempo estriado" (BOULEZ, 1972, p. 88).

7 Aglutinação oriunda do alemão, "Finger" (dedo) e " Schlag” (bater, colidir) (MESSINA, p. 25).

\section{Referências}

BOULEZ, Pierre. A música hoje. São Paulo: Perspectiva, 1972. p. 149.

CARDOSO, Cláudio U. P. Performance de harmônicos naturais com a técnica de nodo duplo aplicada ao violoncelo. Per Musi. Belo Horizonte, v. 1, 2000. p. 77-88.

FALLOWFIELD, Ellen. Cello Map: A Handbook of Cello Technique for Performers and Composers. Tese de Doutorado. University of Birmingham, 2009. Birmingham: 2009. 208p.

FERRAZ, Silvio. Entrevista de Kalyne Valente em Outubro de 2013. Rio de Janeiro. Anotações de ensaio. XX Bienal de Música Contemporânea Brasileira.

FERRAZ, Silvio. Entrevista de Kalyne Valente em 05, 10 e 12 de Maio de 2014. São Paulo. E-mail. 
MESSINA, Dylan. Where Will it End: or a guide to extended techniques for the violoncello. Monografia. Disponível em: <http://www.oberlin.edu/library/friends/researchaward/messina.pdf>. Acesso em: 01ago2014.

PADOVANI, José Henrique e FERRAZ, Silvio. Proto-história, Evolução e Situação Atual das Técnicas Estendidas na Criação Musical e na Performance. Música Hodie, Goiânia, v. 11, n. 2, p. 11-35, 2011. Disponível em: <https://www.revistas.ufg.br/index.php?journal=musica\&page= article\&op=view\&path\%5B\%5D=21752. Acesso em: 05 ago2014.

PRESGRAVE, Fábio. Apontamento de aulas por Kalyne Valente em 2010 e 2014. Natal. Anotações em aula. UFRN.

STRANGE, Patricia; STRANGE, Allen. The Contemporary Violin: extended performance techniques. Berkeley: University of California Press, 2001. 337 p.

VALENTE, Kalyne T. Abordagens de Estudo e Performance da obra Responsório ao Vento para violoncelo solo de Silvio Ferraz. Dissertação de Mestrado. Universidade Federal do Rio Grande do Norte, 2014. Natal: UFRN, 2014. 36p.

Kalyne Valente - Bacharel em Violoncelo pela Universidade Estadual do Pará (UEPA), Especialista em Práticas Interpretativas do Século XX e XXI e Mestre em Violoncelo com ênfase em Performance na Música Contemporânea pela Universidade Federal do Rio Grande do Norte(UFRN). Atuou como professora de violoncelo do Instituto Bacarelli (SP), Conservatório Pernambucano de Música (PE) e nos Cursos de Extensão da UFRN e UFPA. Como instrumentista atuou na Orquestra Sinfônica do Teatro da Paz (PA), Sinfônica Heliópolis (SP) e Orquestra Sinfônica da Universidade Federal do Rio Grande do Norte (RN). É professora de Violoncelo e Música de Câmara do Conservatório Carlos Gomes (Belém-PA) e atua nas áreas de ensino, pesquisa, performance e orquestra.

Fabio Sorenresgrave - Bacharel e Mestre pela Juilliard Schoolof Music. Foi discípulo de Harvey Shapiro e Joel Krosnick.tuou como solista de orquestras como Qatar Philarmonic, Orquestra Sinfônica Brasileira, OSPA, OSMG, OSINPA dentre outras. Realizou dezenas de estreias e primeiras gravações de compositores como Marisa Rezende, Roberto Vitório, Rodrigo Cichelli e Silvio Ferraz. Foi responsável também pela primeira audição latino-americana de obras para violoncelo de Saariaho e Berio. Foi professor nos festivais de Campos do Jordão, Brasília e Poços de Caldas. E Doutor pela Unicamp e está realizando seu estágio pós-doutoral na WWF - Universitaet de Muenster na Alemanha. É Professor da UFRN.

Silvio Ferraz - Foi professor de composição da Unicamp de 2002 a 2013 e atualmente é professor no departamento de Música da USP. Estudou com Adhemar Campos Filho, Gilberto Mendes, Willy Correa de Oliveira, Brian Ferneyhough, Olivier Toni e Gérard Grisey. Autor de Música e Repetição Contemporânea (São Paulo: Educ/Fapesp, 1997), Livro das Sonoridades (Rio: 7 letras, 2005) e Notas, Atos e Gestos que reúne artigos de compositores brasileiros (Rio: 7 letras). Diretor Pedagógico (2009 e 2010) e Artístico do Festival Internacional de Inverno de Campos do Jordão (2010), premiado pela Fundação Vitae em 2003, pesquisador do CNPQ desde 2005 e professor de composição no Instituto de Artes da UNICAMP desde 2002. Idealizador e primeiro diretor artístico da Camerata Aberta. 